\title{
Conhecimento e utilização de plantas mágico-religiosas por rezadeiras do semiárido da Paraíba, Nordeste do Brasil
}

As plantas mágico-religiosas são instrumentos sagrados nos rituais de reza. O objetivo da pesquisa foi registrar o conhecimento e uso local de plantas mágicoreligiosas utilizadas por rezadeiras, discutindo a importância desse conhecimento. A pesquisa entrevistou todas as rezadeiras do município de Amparo (PB), Nordeste do Brasil. Para a coleta dos dados, utilizou-se da observação direta, entrevista semiestruturada e coleta de material botânico. Foram registradas 23 espécies distribuídas em 23 gêneros e 15 famílias. As famílias Fabaceae ( $5 \mathrm{spp}$.) e Lamiaceae (4 spp.) foram as mais citadas. As espécies mais abordadas pelas rezadeiras foram o pinhão roxo (Jatropha gossypiifolia L.), a arruda (Ruta graveolens L.) e o muçambê (Cleome spinosa (Jacq.) Raf.). As enfermidades tratadas através das rezas com uso das plantas variam de 'mal olhado' à 'derrame'. Essa cultura ainda resiste no município, apesar de a nova geração não demonstrar interesse no ofício. Houve alteração das espécies mágico-religiosas utilizadas ao longo do tempo devido talvez às possíveis alterações na vegetação da caatinga, como a inserção das espécies invasoras. É importante promover políticas públicas para incentivar a cultura das rezadeiras, e assim, fomentar a aproximação, respeito e conservação das plantas mágico-religiosas.

Palavras-chave: Etnobotânica; Plantas simbólicas; Cultura das rezas.

\section{Knowledge and use of magical-religious plants by meadows from the semiarid state of Paraíba, Northeast Brazil}

\begin{abstract}
Magical-religious plants are sacred instruments in praying rituals. The aim of the research was to register the knowledge and local use of magical-religious plants used by mourners, discussing the importance of this knowledge. The survey interviewed all mowers in the municipality of Amparom (PB), Northeast Brazil. For data collection, direct observation, semi-structured interviews and collection of botanical material were used. We recorded 23 species distributed in 23 genera and 15 families. The Fabaceae ( $5 \mathrm{spp}$.) and Lamiaceae ( $4 \mathrm{spp}$.) Families were the most cited. The species most approached by the mowers were the purple pine nut (Jatropha gossypiifolia L.), the rue (Ruta graveolens L.) and the muçambê (Cleome spinosa (Jacq.) Raf.). Diseases treated through prayers with plant use range from 'evil eye' to 'spill'. This culture still resists in the city, although the new generation does not show interest in the craft. There was a change in the magicalreligious species used over time, perhaps due to possible changes in the caatinga vegetation, such as the insertion of invasive species. It is important to promote public policies to encourage the culture of mourners, and thus promote the rapprochement, respect and conservation of magical-religious plants.
\end{abstract}

Keywords: Ethnobotany; Symbolic plants; Prayer culture.

Topic: Uso dos Recursos Naturais

Reviewed anonymously in the process of blind peer.
Received: 13/10/2018

Approved: $12 / 11 / 2018$
Amanda Lucena Coutinho id

Universidade Federal da Paraíba, Brasil http://lattes.cnpq.br/7085391393114086 http://orcid.org/0000-0002-2806-0713

amanda bispo@hotmail.com

Reinaldo Farias Paiva de Lucena (D)

Universidade Federal da Paraíba, Brasil

http://lattes.cnpq.br/0588527774815010

http://orcid.org/0000-0003-4775-7775

rlucena@dse.ufpb.br

Kallyne Machado Bonifácio (iD

Universidade Federal da Paraíba, Brasil

http://lattes.cnpq.br/8240555685711403

http://orcid.org/0000-0002-0767-9226

kallynebonifacio@gmail.com

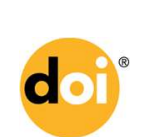

DOI: 10.6008/CBPC2179-6858.2018.008.0021
Referencing this:

COUTINHO, A. L.; LUCENA, R. F. P.; BONIFÁCIO, K. M.. Conhecimento e utilização de plantas mágico-religiosas por rezadeiras do semiárido da Paraíba, Nordeste do Brasil. Revista Ibero-Americana de Ciências Ambientais, v.9, n.8, p.235-248, 2018. DOI: http://doi.org/10.6008/CBPC2179-6858.2018.008.0021 


\section{INTRODUÇÃO}

O uso de plantas em rituais religiosos é uma das mais antigas práticas realizadas pelas populações locais (SHARMA et al., 2011). As plantas mágico-religiosas são consideradas objetos sagrados de muito prestígio pelas comunidades locais (ALBUQUERQUE et al., 1994), sendo instrumentos para os especialistas locais, dentre eles as denominadas rezadeiras (ARRUDA-CAMARGO, 2006). Esses agentes sociais dentro das comunidades também são chamados de benzedeiras, as quais executam a prática das rezas acionando um mundo material e simbólico de conhecimentos do catolicismo popular para restabelecer a saúde física e espiritual das pessoas que as procuram (SANTOS, 2009). Além das mulheres, também pode-se encontrar homens exercendo essa atividade no interior do semiárido do Nordeste do Brasil.

Albuquerque et al. (1994) acredita que as propriedades terapêuticas das plantas são norteadas pelas propriedades mágicas, isto é, são essas virtudes que operam as melhoras dos males que acometem as pessoas e a comunidade. Essas plantas estão inseridas em um mundo de significados particulares, ou seja, não possui explicação biológica (VERDE, et al., 1997), e sim respostas das forças sobrenaturais em uma atmosfera de fé (ZANK et al., 2016), sendo utilizadas para o cuidado e tratamento das doenças espirituais, sociais e físicas (SHARMA et al., 2011).

Vários grupos humanos, a exemplo dos quilombolas, indígenas e agricultores, utilizam-se das plantas em seus rituais místicos e religiosos desde a antiguidade (SHARMA et al., 2011), utilizando-as para banhos, rezas e cerimônias. No cenário mundial, o uso das plantas é bastante relevante, principalmente nos aspectos voltados à saúde e mágicos (BARROS, 2014).

Em uma comunidade afrodescendente residente na cidade de Recife, Pernambuco, por exemplo, é comum o uso de plantas mágico-religiosas baseando-se em crenças, símbolos ou sinais, das quais várias espécies como a quixaba (Bumelia sartorum Mart.), hortelã-da-folha-graúda (Plectranthus amboinicus (Lour.) Spreng.) e alfavaca-de-caboclo (Ocimum gratissimurn L.) são indicadas para doenças espirituais atribuídas a espíritos malignos ou para evitar castigo devido a violação das leis dos deuses tradicionais (ALBUQUERQUE, 2001). Muito usual o uso mágico das plantas por essas populações, o que pode ser explicado pela matriz religiosa, sendo as mesmas praticantes dos ritos do candomblé e umbanda, por exemplo.

Nesse contexto, estudos foram realizados no semiárido brasileiro evidenciando a importância das plantas mágico-religiosas para as comunidades locais (ALBUQUERQUE et al., 1994), sendo utilizadas em rezas, rituais, banhos, proteção, entre outros (FREITAS, 2014). Sendo de grande importância nesse registro, as pesquisas etnobotânicas, as quais buscam compreender as inter-relações homem-planta desde suas interações naturais, simbólicas e também culturais, além de contribuir para a valorização e conservação do conhecimento tradicional relacionado às plantas (GOMES et al., 2017; SILVA, et al., 2014; ALBUQUERQUE, 2005).

Há que se destacar que, em pesquisas etnobotânicas, o uso das plantas mágico-religiosas é documentado juntamente com as demais categorias de uso (ARÉVALO-MARÍN et al., 2015; ALVES et al., 2014; GUERRA, 2012; CORTÉS, 2010; ROQUE et al., 2010; LUCENA et al., 2008; LUCENA et al., 2007; FERRAZ et al., 
2006), sendo considerado menos expressivo no contexto geral quando comparado a categorias como medicinal e as de uso madeireiro (construção e combustível, por exemplo).

Esse uso tem sido pouco enfatizado pelas comunidades locais, apesar de ser frequente nas práticas de rezas (OLIVEIRA et al., 2009). Tal fato pode estar ocorrendo devido às mudanças socioculturais e ecológicas ao longo do tempo, pois o conhecimento tradicional é dinâmico (ZENT, 2013). Estudos já tratam essas mudanças associando-as à universalização e ampliação da saúde, a perda de identidade cultural e avanço da urbanização, acarretando um constante desuso das práticas com plantas na região (MUNIZ et al., 2016; HOFFMANN-HOROCHOVSKI, 2012; ALVES et al., 2007).

Arévalo-Marín et al. (2015), trabalhando com categorias de uso de plantas em uma comunidade rural do semiárido paraibano, identificaram espécies que correm o risco de serem esquecidas por serem pouco citadas, caracterizando assim uma possível perda de diversidade cultural. Arévalo-Marín et al. (2015) discorre, ainda, que a erosão desse saber pode estar associada à globalização, o que tem afetado principalmente os mais jovens.

Na tentativa de valorizar e registrar as práticas das rezadeiras do município de Amparo, no semiárido da Paraíba, e aprofundar os conhecimentos sobre as plantas com significado simbólico, este estudo teve como objetivo registrar o conhecimento e o uso local de espécies de plantas nativas e exóticas com propriedades mágico-religiosas utilizadas por pessoas que se dizem rezar, discutindo a importância da manutenção desse conhecimento.

De forma mais específica, buscou-se levantar quais espécies são utilizadas como mágico-religiosas pelas rezadeiras, identificar as formas de obtenção das plantas mágico-religiosas e descrever as funções atribuídas a essas plantas, enfatizando a forma de obtenção do conhecimento sobre elas. Diante do proposto, parte-se do pressuposto de que o conhecimento e uso de plantas com propriedades mágico-religiosas no semiárido da Paraíba estão se perdendo ao longo das gerações e que as rezadeiras estão desaparecendo, principalmente em virtude de a nova geração não desejar assumir esse ofício.

\section{MATERIAIS E MÉTODOS}

\section{Área de estudo}

Este estudo foi realizado no município de Amparo (figura 1) localizado na microrregião do Cariri Ocidental, no estado da Paraíba, Nordeste do Brasil. Distante 314km da cidade de João Pessoa, capital do Estado, possuindo uma área territorial de $122 \mathrm{~km}^{2}$, com população estimada em 2.088 habitantes (1.062 na zona urbana e 1.026 na zona rural).

O município de Amparo encontra-se inserido nos domínios da bacia hidrográfica do rio Paraíba, na Região do Alto Paraíba, incluído na área geográfica de abrangência do semiárido brasileiro, definido pelo Ministério da Integração Nacional em 2005 (BRASIL, 2005). A vegetação é composta por caatinga com trechos de Floresta Caducifólia. Na agricultura se produz feijão, milho, algodão, goiaba, manga e caju. Na pecuária, predomina a caprinocultura, além da criação de aves, ovinos e bovinos (AMPARO, 2017). 


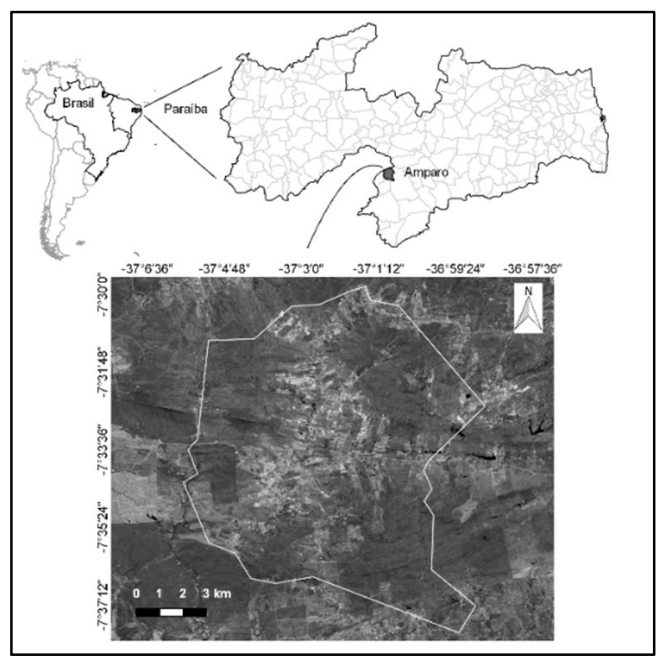

Figura 1: Localização do município de Amparo, Paraíba, Nordeste do Brasil.

\section{Público-Alvo}

A pesquisa foi realizada com $100 \%$ ( $n=10)$ das rezadeiras residentes no município de Amparo (3 na zona urbana e 7 na zona rural). Todas tiveram sua origem na zona rural onde aprenderam e iniciaram a prática das rezas. A seleção das informantes ocorreu pelo método bola de neve ('Snow Ball') (BAILEY, 1994), o qual consiste em uma amostragem não-probabilística (ALBUQUERQUE et al., 2010) que seleciona o público alvo de forma intencional. Portanto, foram iniciadas as visitas através de uma rezadeira que se mostrou disposta a contribuir com a pesquisa, a qual indicou a próxima rezadeira a ser entrevistada. Assim, foram alcançadas todas as mulheres atuantes na prática da reza no município.

No primeiro contato foi explicado sobre a pesquisa e solicitado o consentimento de participação, assinando assim o Termo de Consentimento Livre Esclarecido - TCLE, aprovado pelo Comitê de Ética em Pesquisa (CEP) da Universidade Federal da Paraíba (UFPB) (CEP/UFPB no 2.613.549), conforme estabelece a Resolução no 466/2012 do Conselho Nacional de Saúde.

\section{Procedimentos metodológicos}

Inicialmente utilizou-se da observação direta (ALBUQUERQUE et al., 2008; ALBUQUERQUE et al., 2010), a fim de conhecer a cultura das rezadeiras (ambiente, rituais e relação com a vegetação). As visitas ocorreram através de agendamento prévio onde foram realizadas as entrevistas através de formulários semiestruturados divididos em duas partes.

A primeira parte, abordou questões referentes ao perfil das entrevistadas (como por exemplo, idade, sexo, escolaridade, ocupação, tempo de moradia no município, estado civil). Na segunda parte, foram solicitadas informações sobre as plantas mágico-religiosas (nome das plantas, indicações de usos, local, forma de obtenção e os aspectos relativos à obtenção do conhecimento sobre a planta). Também se abordou perguntas relativas à possível associação do emprego místico da planta com seu poder curativo e medicinal.

A diversidade de plantas utilizadas nos rituais de reza foi obtida por meio da lista livre que permite conhecer a variedade de plantas além de identificar variações intraculturais relacionadas ao seu nome popular (ALBUQUERQUE et al., 2010). A coleta de espécimes foi efetuada através de uma turnê-guiada 
(ALBUQUERQUE et al., 2010) contando com o auxílio das rezadeiras. A turnê guiada é uma técnica de entrevista em campo onde o informante aponta as espécies ao pesquisador, dirimindo dúvidas que possam surgir durante a entrevista, como também possibilitando a coleta do material específico (ALBUQUERQUE et al., 2010).

As plantas coletadas foram encaminhadas ao Laboratório de Botânica da Universidade Estadual da Paraíba - UEPB e foram herborizadas, identificadas e depositadas no herbário Arruda Câmara da UEPB. Ao final da pesquisa foram realizadas 30 visitas, três em cada residência onde havia uma rezadeira. A primeira visita foi para a observação e uma conversa informal com a finalidade de estabelecer uma relação de confiança entre as entrevistadas. Na segunda visita foram realizadas as entrevistas e na terceira foi coletado o material botânico indicado pelas rezadeiras.

\section{RESULTADOS E DISCUSSÃO}

\section{Características socioeconômicas das rezadeiras}

Foram entrevistadas 10 rezadeiras residentes no município de Amparo, todas do sexo feminino, com idade acima de 49 anos, das quais 7 (70\%) têm mais de 60 anos, enquadrando-se como idosas, de acordo com a faixa de idade estabelecida pelo Estatuto do Idoso (BRASIL, 2003) (tabela 1). No geral, a literatura traz que a prática das rezadeiras é exercida pelos mais velhos, corroborando assim com o presente estudo (MACIEL et al., 2006; OLIVEIRA et al., 2009; HOFFMANN-HOROCHOVSKI, 2012; ZANK et al., 2016). Essas mulheres possuem vida simples, sendo $80 \%(n=8)$ alfabetizadas, nascidas nas zonas rurais do município de Amparo, Paraíba $(n=6 ; 60 \%)$ e Sumé, Paraíba $(n=4 ; 40 \%)$ através de parteiras (mulheres que realizavam o parto nas residências). Atualmente, os partos são realizados nos hospitais e as parteiras não exercem mais essa prática.

Sobre a ocupação, nenhuma das entrevistadas considerou a atividade de rezadeira como profissão, sendo que para $50 \%$ delas a agricultura é a principal fonte de renda. 0 ofício das rezas pode ser classificado como profissão por exigir disponibilidade de tempo, disposição física e mental, além do papel solidário em contribuir para saúde da população. Em um contexto socioeconômico, aborda-se que a prática das rezas deve ser registrada, de modo que possa ser associada aos serviços médicos, complementando o tratamento das enfermidades, garantindo assim maiores benefícios à população local e valorizando a cultura, uma vez que por muitos anos esta prática era o único tratamento de saúde das populações.

Tabela 1- Características socioeconômicas das 10 rezadeiras residentes no município de Amparo, Paraíba, Brasil.

\begin{tabular}{|l|c|c|}
\hline Aspectos Sociais & \multicolumn{2}{|c|}{ Números de entrevistados } \\
\hline Idade & 3 & $30 \%$ \\
\hline 40 a 60 anos & 7 & $70 \%$ \\
\hline$>60$ anos & & $80 \%$ \\
\hline Escolaridade (alfabetizadas) & 8 & $20 \%$ \\
\hline Sim & 2 & $60 \%$ \\
\hline Não & & $40 \%$ \\
\hline Naturalidade & 6 & \\
\hline Amparo, Paraíba & 4 & \\
\hline Sumé, Paraíba & & \\
\hline Ocupação & & \\
\hline
\end{tabular}




\begin{tabular}{|c|c|c|}
\hline Agricultora & 5 & $50 \%$ \\
\hline Aposentada & 3 & $30 \%$ \\
\hline Dona de casa & 2 & $20 \%$ \\
\hline \multicolumn{3}{|l|}{ Religião } \\
\hline Católicas & 10 & $100 \%$ \\
\hline \multicolumn{3}{|c|}{ Tempo de atividade na reza (anos) } \\
\hline 10 a 30 & 6 & $60 \%$ \\
\hline$>30$ & 4 & $40 \%$ \\
\hline \multicolumn{3}{|l|}{ Filhos } \\
\hline Sim & 9 & $90 \%$ \\
\hline Não & 1 & $10 \%$ \\
\hline
\end{tabular}

O ritual de reza executado pelas entrevistadas consiste na utilização de galhos com folhas verdes, ou apenas as folhas, benzendo a pessoa enferma com movimentos em forma de cruz e realizando orações a Deus e aos santos católicos. Todas as rezadeiras se declararam católicas (tabela 1) e possuíam em suas casas quadros com imagens dos santos católicos. As rezas costumam ser longas e a rezadeira não pode ser interrompida durante o ritual, pois, sendo assim, terá que iniciá-lo novamente. Essas especialistas locais reconhecem que ser rezadeira é dom de Deus e que não se pode negar uma reza aos necessitados. Elas afirmam que são usadas por Deus para retirar as enfermidades dos necessitados, mas reforçam que 'é a fé que é capaz de curar'.

A rezadeira menos experiente exerce a atividade há 10 anos, mostrando que o conhecimento local dessa atividade não está sendo repassado há mais de uma década. A transmissão desse saber ocorre oralmente e por meio dos gestos, normalmente de pais para filhos (OLIVEIRA et al., 2009). Essa transmissão é definida pela literatura como transmissão de conhecimento vertical (SOLDATI et al., 2015).

Nesta pesquisa, foi observado que, apesar de $90 \%$ das entrevistadas $(n=9)$ terem filhos, nenhum deles demonstrou interesse em adquirir os conhecimentos das mães. As rezadeiras afirmaram que a nova geração não tem tanta fé e disposição em aprender as rezas. Apontam como causa às mudanças no estilo de vida acarretado pelo crescimento da urbanização, universalização da medicina convencional e acesso facilitado aos meios de comunicação como televisão, celulares e computadores.

Albuquerque et al. (2007) corrobora com essa compreensão sobre mudanças no estilo de vida, e acrescenta ainda que as interferências causadas pela internet e redes sociais tem provocado redução no tempo de vivência das novas gerações com os familiares mais antigos, prejudicando assim a transmissão do conhecimento cultural. A redução na transmissão desse conhecimento pode se tornar um futuro processo de aculturação como revela Carvalho et al. (2012) em sua pesquisa sobre o uso de plantas e a transmissão do conhecimento em uma comunidade rural de Lagoa, Paraíba, constatando que $27 \%$ dos entrevistados não se preocupam com o repasse do conhecimento cultural.

\section{Levantamento etnobotânico e funções mágico-religiosas das plantas}

Foram registradas 23 espécies distribuídas em 23 gêneros e 15 famílias (tabela 2). As famílias Fabaceae ( 5 spp.) e Lamiaceae (4 spp.) foram as mais citadas. As espécies mais abordadas e com maior relevância para as rezadeiras foram o pinhão roxo (Jatropha gossypiifolia L.), a arruda (Ruta graveolens L.) e o muçambê (Tarenaya spinosa (Jacq.) Raf.), com 70\%, 50\% e 40\% do total das citações, respectivamente. 
Tabela 2: Levantamento etnobotânico das plantas mágico-religiosas usadas pelas rezadeiras do Município de Amparo,

Paraíba, Brasil.

\begin{tabular}{|c|c|c|c|c|}
\hline $\begin{array}{l}\text { Família/espécie } \\
\text { (nome local) }\end{array}$ & $\begin{array}{l}\text { № de } \\
\text { citações }\end{array}$ & $\begin{array}{l}\text { Indicações } \\
\text { uso mágico }\end{array}$ & $\begin{array}{l}\text { Indicações } \\
\text { medicinal }\end{array}$ & $\begin{array}{l}\text { No } \\
\text { tombo }\end{array}$ \\
\hline \multicolumn{5}{|l|}{ Amaranthaceae } \\
\hline $\begin{array}{l}\text { Chenopodium ambrosioides } \mathrm{L} \text {. } \\
\text { (matruz) }\end{array}$ & 3 & mau-olhado, dor de cabeça e "desmitido" (torção) & $\begin{array}{l}\text { xarope (tosse, gripe) e chá } \\
\text { (infeç̧ão, gastrite) }\end{array}$ & 1878 \\
\hline \multicolumn{5}{|l|}{ Anmonaceae } \\
\hline Annona squamosa L. (pinha) & 1 & $\begin{array}{l}\text { mau-olhado, ferimento, queimadura e "desmitido" } \\
\text { (torção) }\end{array}$ & - & 1879 \\
\hline \multicolumn{5}{|l|}{ Cleomaceae } \\
\hline $\begin{array}{l}\text { Tarenaya spinosa (Jacq.) Raf. } \\
\text { (muçambê) }\end{array}$ & 4 & \multicolumn{3}{|c|}{ mau-olhado e "vermelhão" (erisipela) gripe e tosse (faz o lambedor) } \\
\hline \multicolumn{5}{|l|}{ Convovulaceae } \\
\hline $\begin{array}{l}\text { Ipomoea carnea Jacq. } \\
\text { (mucambo ou oliveira) }\end{array}$ & 2 & Mau-olhado & - & 1881 \\
\hline \multicolumn{5}{|l|}{ Euphorbiaceae } \\
\hline $\begin{array}{l}\text { Jatropha gossypiifolia L. } \\
\text { (pinhão-roxo) }\end{array}$ & 7 & $\begin{array}{l}\text { mau-olhado, energias ruins, "desmitido" (torção), } \\
\text { vermelhão (erisipela), ferimento, derrame e proteger } \\
\text { a casa. }\end{array}$ & Dor de dente (chá) & 1882 \\
\hline \multicolumn{5}{|l|}{ Fabaceae } \\
\hline Cassia siamea Lam. (canafístula) & 3 & $\begin{array}{l}\text { mau-olhado, esmurecimento, queimadura, ferida de } \\
\text { boca, dor de cabeça e quebradeira no corpo. }\end{array}$ & - & 1883 \\
\hline $\begin{array}{l}\text { Leucaena leucocephala (Lam.) } \\
\text { de Wit. (linhaça) }\end{array}$ & 1 & $\begin{array}{l}\text { Mau-olhado, "desmitido" (torção), vermelhão } \\
\text { (erisipela) e derrame. }\end{array}$ & - & 1884 \\
\hline $\begin{array}{l}\text { Cenostigma pyramidale (Tul.) } \\
\text { Gagnon \& G. P. Lewis. } \\
\text { (catingueira) }\end{array}$ & 2 & $\begin{array}{l}\text { Mau-olhado, ferida de boca, dor de cabeça, } \\
\text { "esmurecimento" (cansaço), quebradeira no corpo e } \\
\text { queimadura. }\end{array}$ & - & 1885 \\
\hline $\begin{array}{l}\text { Senna ocidentalis (L.) Link. } \\
\text { (pagé ou majiroba) }\end{array}$ & 3 & $\begin{array}{l}\text { Mau-olhado, vermelhão, ferida de boca, dor de } \\
\text { cabeça, "esmurecimento" (cansaço), queimadura e } \\
\text { quebradeira no corpo. }\end{array}$ & - & 1886 \\
\hline $\begin{array}{l}\text { Prosopis juliflora (SW) DC } \\
\text { (algaroba) }\end{array}$ & 3 & Mal olhado, dor de cabeça e "desmitido" (torção) & - & 1887 \\
\hline \multicolumn{5}{|l|}{ Lamiaceae } \\
\hline $\begin{array}{l}\text { Lippia sidoides Cham. (alecrim } \\
\text { silvestre) }\end{array}$ & 2 & Mau-olhado, dor de cabeça e "desmitido" (torção). & - & 1888 \\
\hline $\begin{array}{l}\text { Mentha piperita L. (hortelã } \\
\text { pimenta) }\end{array}$ & 1 & $\begin{array}{l}\text { Mau-olhado, "desmitido" (torção), "vermelhão" } \\
\text { (erisipela) e derrame. }\end{array}$ & chá (derrame) & - \\
\hline $\begin{array}{l}\text { Rosmarinus officinalis L. } \\
\text { (alecrim tempero) }\end{array}$ & 2 & Mau-olhado, dor de cabeça e desmitido (torção). & chá (febre e dores) & - \\
\hline $\begin{array}{l}\text { Ocimum basilicum L. } \\
\text { (manjericão) }\end{array}$ & 2 & $\begin{array}{l}\text { Mau-olhado, vermelhão, dor de cabeça, "desmitido" } \\
\text { (torção), evita derrame, limpeza das energias ruins da } \\
\text { casa. }\end{array}$ & - & - \\
\hline \multicolumn{5}{|l|}{ Malvaceae } \\
\hline $\begin{array}{l}\text { Gossypium hirsutum L. } \\
\text { (algodão) }\end{array}$ & 1 & mau-olhado e "desmitido" (torção) & $\begin{array}{l}\text { afinar o sangue e furúnculo } \\
\text { (põe os caroços do algodão } \\
\text { na cachaça e bebe). }\end{array}$ & 1889 \\
\hline \multicolumn{5}{|l|}{ Meliaceae } \\
\hline $\begin{array}{l}\text { Azadirachta indica A. Juss. } \\
\text { (aroeira do pará, vitória, estrela } \\
\text { do norte ou nim) }\end{array}$ & 3 & $\begin{array}{l}\text { Mal olhado, vermelhão (erisipela), esmurecimento, } \\
\text { queimadura, ferida de boca, quebradeira no corpo, } \\
\text { dor de cabeça, desmitido (torção), derrame. }\end{array}$ & repelente de mosquitos & 1890 \\
\hline \multicolumn{5}{|l|}{ Moraceae } \\
\hline Ficus Benjamina L. (fícus) & 1 & mau-olhado & $\overline{\bar{C}}$ & 1891 \\
\hline \multicolumn{5}{|l|}{ Moringaceae } \\
\hline Moringa oleífera Lam. (jarrim) & 1 & $\begin{array}{l}\text { mau-olhado, "desmitido" (torção), vermelhão } \\
\text { (erisipela, evita derrame }\end{array}$ & $\begin{array}{l}\text { as sementes limpam a água } \\
\text { barrenta }\end{array}$ & 1892 \\
\hline \multicolumn{5}{|l|}{ Plantaginaceae } \\
\hline Scoparia dulcis L. (vassourinha) & 2 & $\begin{array}{l}\text { mau-olhado, extrair as energias ruins, ferimento e } \\
\text { "desmitido" (torção). }\end{array}$ & - & 1893 \\
\hline \multicolumn{5}{|l|}{ Rhamnaceae } \\
\hline $\begin{array}{l}\text { Ziziphus joazeiro Mart. } \\
\text { (juazeiro) }\end{array}$ & 3 & $\begin{array}{l}\text { mau-olhado, "desmitido" (torção), esmurecimento, } \\
\text { queimadura, dor de cabeça e ferida de boca (reza) ou } \\
\text { utilizando um colar confeccionado com as folhas. }\end{array}$ & tosse & 1894 \\
\hline \multicolumn{5}{|c|}{ 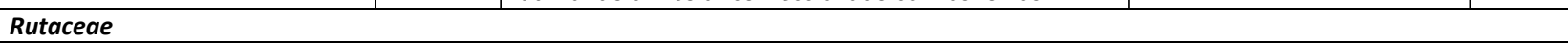 } \\
\hline Ruta grveolens L. (arruda) & 5 & $\begin{array}{l}\text { mau-olhado, energias ruins, dor de cabeça e } \\
\text { "desmitido" (torção), vermelhão (erisipela), derrame, } \\
\text { proteger a casa. }\end{array}$ & $\begin{array}{l}\text { dor de ouvido, } \\
\text { cólica (Chá) }\end{array}$ & - \\
\hline \multicolumn{5}{|l|}{ Solanaceae } \\
\hline $\begin{array}{l}\text { Nicotiana Glauca Graham (para- } \\
\text { raio ou oliveira) }\end{array}$ & 5 & mau-olhado & - & 1895 \\
\hline \multicolumn{5}{|l|}{ Verbenaceae } \\
\hline $\begin{array}{l}\text { Lippia alba (Mil.) N. E. Br } \\
\text { (cidreira) }\end{array}$ & 1 & Mau-olhado, dor de cabeça e "desmitido" (torção) & - & 1896 \\
\hline
\end{tabular}


O pinhão roxo (J. gossypiifolia), natural das Antilhas e América tropical, é bastante cultivado no Brasil, principalmente na região Nordeste pelo seu poder mágico e também medicinal (LORENZI et al., 2008). Essa espécie é utilizada nas rezas para mal olhado, energias ruins, desmentido (torção), derrame e vermelhão (infecção de pele). Além de utilizada nos rituais de rezas, J. gossypiifolia também é empregada para proteger o lar dos males espirituais quando plantadas ao redor da casa. O chá de suas folhas também possui efeito medicinal na cura de dor de dente.

A arruda (R. graveolens), natural do Mediterrâneo e da Ásia Menor, conhecida pelos poderes mágicos desde a antiguidade, também bastante cultivada no Brasil, principalmente na região Nordeste (LORENZI et al., 2008), foi citada pelas rezadeiras como planta forte para as rezas, mas também considerada difícil de ser utilizada pela sua indisponibilidade. De acordo com uma das entrevistadas que cultiva essa espécie em seu jardim, não se pode contar sempre com $R$. graveolens para as rezas, pois ela necessita de um tempo longo para regeneração dos seus galhos.

O Muçambê (T. spinosa) é uma planta nativa do Brasil e possui domínio também na Caatinga (Floresta Seca) (LORENZI, 2008). É indicada para rezar mal olhado e vermelhão e também tem uso medicinal através do lambedor feito com suas flores, que atua na cura da gripe e da tosse. J. gossypiifolia (pinhão-roxo) e $R$. graveolens (arruda) são espécies de plantas bastante utilizadas principalmente para uso mágico-religioso (ALBUQUERQUE et al., 2002; ALBUQUERQUE et al., 2007; OLIVEIRA et al., 2009; KAWA, 2012; BITENCOURT et al., 2014; FONSECA et al., 2017), enquanto T. spinosa tem sido abordado na literatura devido ao seu uso medicinal (ROQUE et al., 2010; COSTA et al., 2016). Theotonio (2010) enfatiza os poderes mágicos da $R$. graveolens e J. gossypiifolia sendo indicados contra mal olhado, feitiçarias, energias ruins e também como amuleto de proteção.

O juazeiro (Ziziphus joazeiro Mart.), o mastruz (Chenopodium ambrosioides L.) e o manjericão (Ocimum basilicum L.), apesar de terem sido pouco citadas pelas rezadeiras, quando mencionadas, foram bastante enfatizadas pela sua relevância mágica, tanto no tratamento de enfermidades como também para outros usos mágicos.

O juazeiro (Z. joazeiro), planta nativa e endêmica do Brasil, é bastante utilizado pelas comunidades locais, permanecendo verde durante todo o ano (LORENZI et al., 2008). Kury (2012) considera essa espécie como uma das mais representativas da Caatinga. As rezadeiras entrevistadas afirmaram utilizar apenas as folhas dessa espécie para os rituais de reza e não os galhos como acontece com a maioria das outras plantas, devido aos seus espinhos. A 'ferida de boca', enfermidade tratada com rezas, também pode ser curada quando o doente utiliza um colar feito com as folhas do juazeiro até que fique completamente curado. $O$ lambedor feito com suas folhas também é empregado para tratar a tosse.

As comunidades do nordeste brasileiro atribuem diversas utilidades a espécie Z. joazeiro (juazeiro), como combustível, alimentício, medicinal, veterinário, entre outros (SILVA et al., 2014; AREVALO-MARIN et al., 2015). O uso mágico-religioso atribuído a essa espécie é pouco expressivo na literatura, no entanto, além do uso pelas rezadeiras dessa pesquisa, tem-se o trabalho de Guerra (2012) realizado na zona rural do município de São Mamede, Paraíba, que observaram esse uso, além dos demais. 
O mastruz (C. ambrosioides) é utilizado nas rezas para combater e curar o mal olhado, a dor de cabeça e desmitido (torção). Também foi apontado pelas entrevistadas devido suas propriedades medicinais, pois, através do chá, cura-se problemas gastrointestinais (gastrite) e do xarope, trata-se problemas respiratórios, como a gripe e a tosse. Esse achado, corrobora com os estudos de Costa et al. (2016), que estudou as plantas medicinais em uma comunidade do município de Picuí na Paraíba. Os estudos etnobotânicos realizados no Nordeste brasileiro enfatizam os fins medicinais dessa espécie (MAIOLI-AZEVEDO et al., 2007; ALVES et al., 2014; SANTOS et al., 2017), sendo indicada para diversas enfermidades como verminoses, tosse, catarro, febre e diarreia (BRITO et al., 2015).

O manjericão (O. basilicum) natural da Ásia, bastante utilizado no Brasil (LORENZI et al., 2008) é indicado para rezar mal olhado, vermelhão (erisipela), dor de cabeça, desmitido (torção) e derrame. Além de ser usado nas rezas, também é indicado para retirar e bloquear as energias ruins da casa, mergulhando as folhas da planta na água e despejando-a nos quatro cantos da casa, procedimento relatado por uma das entrevistadas.

Apesar de algumas pesquisas documentarem o uso mágico-religioso de $O$. basilicum (OLIVEIRA et al., 2009; KAWA, 2012; ALBUQUERQUE et al., 1994), a maioria dá ênfase principalmente às propriedades farmacológicas e medicinais dessa espécie (DANTAS, 2007; TAKUA, et al., 2008; ALBERTASSE et al., 2010; SANTOS et al., 2017). Lorenzi et al. (2008) destaca algumas funções medicinais de $O$. basilicum, afirmando que se trata de uma erva restaurativa que alivia espasmos, melhora a digestão, baixa a febre, além de atuar na cura de infecções bacterianas e parasitas intestinais.

De todas as espécies indicadas ( $n=23), 8$ (35\%) foram citadas apenas uma vez pelas rezadeiras, sendo elas, a hortelã pimenta (Mentha piperita L.), cidreira (Lippia alba (Mil.) N. E. Br.) e para-raio (Nicotiana Glauca Graham), já mencionadas na literatura como plantas mágicas (ALENCAR et al., 2010; FONSECA et al., 2017). Enquanto as demais ( $n=5 ; 22 \%)$, foram incluídas nas práticas de rezas mais pelo fator disponibilidade, do que por sua eficiência.

Plantas como o nin (Azadirachta indica A. Juss.), a algaroba (Prosopis juliflora (SW) DC) e o ficus (Ficus Benjamina L.), destacam-se por serem consideradas espécies invasoras da Paraíba (FABRICANTES et al., 2017), de modo que, por estarem verdes o ano todo, são utilizadas pelas rezadeiras como uma alternativa na ausência das demais. Segundo relato de uma das rezadeiras, essas plantas são 'fracas' e quando utilizadas para "rezas fortes" deixam-na doente, afirmando, portanto, que, devido à indisponibilidade de plantas fortes o ano todo, tem rezado apenas nos familiares e vizinhos.

Constatou-se nesse estudo que as plantas mágicas estão associadas às rezas e à fé na cura, mas algumas também apresentam propriedades medicinais. Kawa (2012) considera que as plantas mágicas podem ser vistas como plantas medicinais pelo seu poder de cura, apesar da forma de usar ser diferente. $O$ autor coloca ainda a importância de preservar as plantas mágicas para manutenção da agrobiodiversidade, pois as plantas são valorizadas pelo seu uso simbólico e prática sociocultural.

Bussman (2016), em sua pesquisa com plantas mágicas acredita que as propriedades alucinógenas das plantas são necessárias para fazer com que os usuários entrem em contato com as divindades, 
espiritualidade, considerando assim a função mágica das plantas. Por outro lado, alguns estudos discordam do efeito mágico religioso das plantas, haja vista que essas plantas possuem propriedades psicoativas que induzem o doente a acreditar na cura, fazendo com que ele se cure com o efeito placebo (ARRUDACAMARGO, 2006; FERREIRA-JÚNIOR et al., 2010).

As indicações de uso mágico-religiosos mencionadas pelas entrevistadas variou de 'mal olhado' a 'derrame', sendo a primeira enfermidade citada por todas as entrevistadas (100\%), seguidas do "desmentido" com 30\% (tabela 3). O 'mal olhado' é a enfermidade tratada por essa cultura que ainda não possui substituto, 'o olhado pode até matar e não tem remédio, nem médico que cure, só a reza' (Rezadeira, 76 anos). Na literatura, essas doenças são bastante mencionadas (OLIVEIRA et al., 2009; ARAÚJO, 2011; KAWA, 2012; BITENCOURT et al., 2014; FREITAS, 2014), sendo curadas pelo poder da reza.

Nessa pesquisa, as rezadeiras não atribuíram a recuperação das enfermidades a espécies de plantas específicas, mas sim às plantas verdes com folhas jovens, capazes de absorver as enfermidades, 'Jesus deixou as plantas para ser instrumento das rezas, as plantas absorvem as doenças' (Rezadeira, 71 anos). No entanto, as entrevistadas apontam que existem plantas que são mais eficientes que outras quanto à absorção, como por exemplo, o pinhão roxo (J. gossypiifolia) e a arruda (R. graveolens), sendo plantas fortes, e a algaroba ( $P$. juliflora) e o nin ( $A$. indica), sendo plantas fracas.

Tabela 3: Indicações terapêuticas das rezas segundo as rezadeiras do Município de Amparo, Paraíba, Brasil.

\begin{tabular}{|l|c|c|}
\hline Doenças tratadas pelas rezadeiras & Números de citações & Frequência relativa (\%) \\
\hline Derrame & 1 & $10 \%$ \\
\hline Queimadura & 1 & $10 \%$ \\
\hline Esmurecimento (cansaço) & 1 & $10 \%$ \\
Dor de cabeça & 2 & $20 \%$ \\
Vermelhão (erisipela) & 2 & $20 \%$ \\
Ferimento/ ferida de boca & 2 & $20 \%$ \\
Desmitido (torção) & 3 & $30 \%$ \\
Mau-olhado & 10 & $100 \%$ \\
\hline
\end{tabular}

Para o tratamento medicinal (tabela 2), as espécies de plantas são tidas como importantes por conta de suas propriedades farmacológicas, diferentemente das plantas de uso mágico-religioso, no qual a reza é o fator preponderante. Araújo et al. (2014) relata que o tema das plantas medicinais é considerado o mais estudado e difundido na etnobiologia por estar associado a várias áreas do conhecimento, principalmente as relacionadas à saúde com relevância para descoberta de novas drogas e medicamentos.

As entrevistadas relataram 10 espécies de plantas (43\%) que também são utilizadas com fins medicinais (tabela 2). Dentre as doenças tratadas, as respiratórias, como tosse e gripe, destacaram-se nas citações ( 3 citações; $30 \%$ do total de citações), onde para tratar tais enfermidades, as plantas como juazeiro (Z. joazeiro), mastruz (C. ambros) e mussambê ( $T$. spinosa) foram as mais relevantes.

Pesquisas sobre plantas medicinais corroboram com essas indicações, acrescentando também problemas gástricos e do fígado, doenças de pele, limpeza dos dentes para Z. joazeiro; vermífugo, problemas estomacais, reumatismo, úlcera, cicatrizante, inflamação e fraturas para o C. ambrosioides, e bronquite, inflamação, umbigo inflamado para o T. spinosa (DANTAS, 2007; LORENZI et al., 2008). 


\section{Formas de obtenção das plantas mágico-religiosas}

As comunidades locais utilizam diferentes critérios para a escolha das plantas. No caso das rezadeiras, o critério exigido é a disponibilidade associada à presença de folhas verdes que possam ser colhidas no momento da reza. Por conta disso, essas plantas são cultivadas nos quintais, jardins e ao redor das residências. As plantas com maior utilidade para as comunidades locais são normalmente cultivadas próximas às casas como forma de facilitar o acesso e a conservação das espécies mais importantes (ALBERTASSE et al., 2010; KAWA, 2012; RITO et al., 2015).

Silva et al. (2018), estudando uma comunidade rural do Piauí, observaram que 85,91\% das residências visitadas possuíam plantas místicas em seus quintais, sendo utilizadas para cura do corpo físico e espiritual, como também para embelezar a área ao redor das casas. Essas plantas ornamentais e mágicas são portadoras de poderes sobrenaturais que protegem a casa de mal olhado e energias ruins, trazem dinheiro e promovem a abertura de caminhos (SIVIERO et al., 2014).

Algumas espécies, por exigirem maior cuidado, são cultivadas em jardins cercados, como a arruda $(R$. graveolens), o manjericão (O. basilicum), a cidreira (L. alba), hortelã pimenta (M. piperita), alecrim tempero (R. officinalis) e o matruz (C. ambrosioides), garantindo a conservação e proteção contra as intempéries ambientais.

\section{CONCLUSÕES}

Mesmo com tanta interferência da sociedade moderna, a cultura das rezas no município de Amparo ainda resiste e vem sendo praticada pelas rezadeiras tanto na zona urbana quanto na rural. No entanto, a importância e valorização dessa cultura vêm sendo aos poucos perdida pelo fato das novas gerações não se interessarem por esse conhecimento.

No passado, a prática das rezadeiras era o único recurso de tratamento de saúde disponível para a população. Todavia, o avanço da urbanização e o acesso facilitado aos meios de comunicação têm provocado redução na frequência das rezas e no uso das plantas. Apesar desse estudo contar com um número considerável de rezadeiras, a maioria relatou esquecimento de alguns rituais, o que pode estar relacionado, provavelmente, a ampliação dos serviços médicos e a disponibilidade de fármacos.

As espécies de plantas mágico-religiosas também têm sofrido modificações dentro da cultura, fato que pode estar associado as possíveis alterações na vegetação da caatinga. Caso, é a inserção de espécies invasoras nas práticas de rezas, como a algaroba $(P$. juliflora) e o nin $(A$. indica). Do ponto de vista da conservação, é bem provável, que essas espécies estejam ganhando espaço nas comunidades do semiárido por sua disponibilidade o ano inteiro. Porém, é possível supor que $P$. juliflora e $A$. indica venham ocupando um espaço que era de espécies nativas, como a jurema ( $M$. hostilis Benth.).

Essa espécie apesar de não ter sido citada nessa pesquisa é muito comum no uso mágico-religioso no semiárido brasileiro. É importante promover políticas públicas para incentivar a cultura das 
rezadeiras que zelam pelo valor místico da vegetação, e assim fomentar a aproximação, respeito e conservação das plantas mágico-religiosas.

\section{REFERÊNCIAS}

AlBeRTASSE, P. D.; ANDRADE, M. A.; THOMAZ, L. D.. Plantas medicinais e seus usos na comunidade da Barra do Jucu, Vila Velha, ES. Revista Brasileira de Plantas Medicinais, v.2, n.1., p.250-260, 2010.

ALBUQUERQUE, U. P.. The use of medicinal plants by the cultural descendants of African people in Brazil. Acta Farmacêutica Bonaerense, v.20, n.2, p.139-144, 2001.

ALBUQUERQUE, U. P.; ANDRADE, L. H. C.. Conhecimento botânico tradicional e conservação em uma área de caatinga no estado de Pernambuco, Nordeste do Brasil. Acta Botânica Brasílica, v.16, n.3, p.273-285, 2002. DOI: http://doi.org/10.1590/S0102-33062002000300004

ALBUQUERQUE, U. P.; CHIAPPETA, A. A.. O uso de plantas e a concepção de doença e cura nos cultos afrobrasileiros. Ciência \& Trópico, v.22, p.197-209, 1994.

ALBUQUERQUE, U. P.; LUCENA, R. F. P., ALENCAR, N. L. Métodos e técnicas para coleta de dados etnobiológicos. In: ALBUQUERQUE, U. P.; LUCENA, R. F. P.; CUNHA, L. V. F. C.. Métodos e técnicas na pesquisa etnobiológica e etnoecológica. Recife: NUPEEA, 2010.

ALBUQUERQUE, U. P.; LUCENA, R. F. P.; LINS NETO, E. M. F.. Seleção e escolha dos participantes da pesquisa. In: ALBUQUERQUE, U. P.; LUCENA, R. F. P.; CUNHA, L. V. F. C.. Métodos e técnicas na pesquisa etnobotânica. 2 ed. Recife: NUPEEA, 2008. p.21-40.

ALBUQUERQUE, U. P.; MONTEIRO, J. M.; RAMOS, M. A., AMORIM, E. L. C.. Medicinal and magic plants from a public market in northeastern Brazil. Journal of Ethnopharmacology, v.110, p.76-91, 2007. DOI: https://doi.org/10.1016/i.jep.2006.09.010

ALENCAR, N. L.; ARAÚJO, T. A. S.; AMORIM, E. L. C.; ALBUQUERQUE, U. P.. The inclusion and selection of medicinal plants in traditional pharmacopoeias: evidence in support of the diversification hypothesis. Economic Botany, v.64, n.1, p.68-79, 2010. DOI:

https://doi.org/10.1007/s12231-009-9104-5

ALVES, C. M.; LUCENA, C. M.; SANTOS, S. S.; LUCENA, R. F. P.; TROVÃO, D. M. B. M.. Ethnobotanical study of useful vegetal species in two rural communities in the semi-arid region of Paraíba state (Northeastern Brazil). Boletim do Museu de Biologia Mello Leitão, v.34, p.75-96, 2014.

ALVES, R. R. N.; SILVA, A. A. G.; SOUTO, W. M. S.; BARBOZA, R. R. D.. Utilização e comércio de plantas medicinais em Campina Grande, PB, Brasil. Revista Eletrônica de Farmácia, v.4, n.2, p.175-198, 2007.

DOI: https://doi.org/10.5216/ref.v4i2.3060

ARAÚJO, F. L.. Representações de doença e cura no contexto da prática popular da medicina: estudo de caso sobre uma benzedeira. Revista Eletrônica de Ciências Sociais, n.18, 2011.
ARAÚJO, T. A. S.; MELO, J. G.; ALBUQUERQUE, U. P.. Introdução à Etnobiologia. Recife: NUPEEA, 2014.

ARÉVALO-MARÍN, E.; LIMA, J. R. F.; PALMA, A. R. T.; LUCENA, R. F. P.; CRUZ, D. D.. Traditional Knowledge in a Rural Community in the Semi-Arid Region of Brazil: Age and gender patterns and their implications for plant conservation. Ethnobotany Researchand Applications, v.14, p.331-344, 2015. DOI:

http://dx.doi.org/10.17348/era.14.0.331-344

ARRUDA-CAMARGO, M. T. L.. Os poderes das plantas sagradas numa abordagem etnofarmacobotânica. Revista do Museu de Arqueologia e Etnologia, v.15, p.395-410, 2006. DOI: https://doi.org/10.11606/issn.24481750.revmae.2006.89745

BAILEY, K. D.. Methods of Social Research. 4 ed. New York, 1994.

BITENCOURT, B. L. G.; LIMA, P. G. C.; BARROS, F. B. Comércio e uso de plantas e animais de importância mágicoreligiosa e medicinal no mercado público do Guamá, Belém do Pará. Revista FSA, v.11, n.3, p.96-158, 2014. DOI: https://dx.doi.org/10.12819/2014.11.3.5

BRASIL. Ministério da Saúde. Estatuto do idoso. Brasília: MS, 2003.

BRASIL. Ministério de Minas e Energia. Diagnóstico do Município de Amparo. Brasília: MME, 2005.

BRITO, M. F. M.; LUCENA, R. F. P.; CRUZ, D. D.. Conhecimento etnobotânico local sobre plantas medicinais: uma avaliação de índices quantitativos. Interciência, v.40, n.3, 2015.

BUSSMANN, R. W.. Magic plants: Introduction to Ethnobiology. Springer, p.163-169, 2016.

CARVALHO, T. K. N.; SOUSA, R. F.; MENESES, S. S. S; RIBEIRO, J. P. O.; FÉLIX, L. P.; LUCENA, R. F. P.. Plantas usadas por uma comunidade rural na Depressão Sertaneja no Nordeste do Brasil. Revista de Biologia e Farmácia, p.92-120, 2012.

CORTÉS, W. A.. Caracterización y usos tradicionales de productos forestales no maderables (PFNM) en el corredor de conservación Guantiva: La Rusia-Iguaque. Revista Colombia Forestal, v.13, n.1, p.117-140, 2010.

COSTA, J. C.; MARINHO, M. G. V.. Etnobotânica de plantas medicinais em duas comunidades do município de Picuí, Paraíba, Brasil. Revista Brasileira de Plantas Medicinais, v.18, n.1, p.125-134, 2016. DOI: http://doi.org/10.1590/1983-084X/15 071

DANTAS, I. C.. O Raizeiro. Campina Grande: EDUEP, 2007. FABRICANTE, J. R.; SANTOS, J. P. B.; ARAÚJO, K. C. T.; COTARELLI, V. M.. Utilização de espécies exóticas na 
arborização e a facilitação para o estabelecimento de casos de invasão biológica. Biotemas, v.30, n.1, p.55-63, 2017. DOI: https://doi.org/10.5007/2175-7925.2017v30n1p55

FABRICANTE, J. R.; SIQUEIRA FILHO, J. A.. Plantas exóticas e invasoras das caatingas do Rio São Francisco. In: SIQUEIRA FILHO, J. A.. A flora das caatingas do Rio São Francisco: história natural e conservação. Rio de Janeiro: Andrea Jakobsson, 2012. p.366-393.

FERRAZ, J. S. F.; ALBUQUERQUE, U. P.; MEUNIER, I. M. J.. Valor de uso e estrutura da vegetação lenhosa às margens do riacho do Navio, Floresta, PE, Brasil. Acta Botânica Brasílica, v.20, n.1, p.125-134, 2006. DOI: http://doi.org/10.1590/S0102-33062006000100012

FERREIRA-JÚNIOR, W. S.; CRUZ, M. P.; VIEIRA, F. J.; ALBUQUERQUE, U. P.. Are hallucinogenic plants efficacious in curing diseases?. Boletín Latino americano y del Caribe de Plantas Medicinales y Aromáticas, v.9, n.4, p.292-301, 2010.

FONSECA, L. M. B.; GARZÓN, A. G. M.; GÓMEZ, M. A. T.. Recuperación etnobotánica del uso tradicional no maderable del bosque secundário en el municipio de Nocaima, Cundinamarca. Revista Mutis, v.7, n.1, p.48-66, 2017. DOI: https://doi.org/10.21789/22561498.1188

FREITAS, C. L.. Uso terapêutico e religioso das ervas. Caminhos, v.12, n.1, p.79-92, 2014.

GUERRA, N. M.. Usos locais de espécies vegetais nativas em uma comunidade rural no semiárido nordestino (São Mamede, Paraíba, Brasil). Biofar, p.184, 2012.

HOFFMANN-HOROCHOVSKI, M. T.. Velhas benzedeiras. Mediações: Revista de Ciências Sociais, v.17, n.2, p.126-140, 2012.

KAWA, N. Magic plants of Amazonia and their contribution to agrobiodiversity. Human Organization, v.71, n.3, p.225233, 2012. DOI: https://doi.org/10.17730/humo.71.3.2125215484378738

KURY, L. B.. Viajantes Naturalistas no Rio São Francisco. In: SIQUEIRA FILHO, J. A.. A flora das caatingas do Rio São Francisco: história natural e conservação. Rio de Janeiro: Andrea Jakobsson, 2012.

LORENZI, H.. Plantas daninhas do Brasil: terrestres, aquáticas, parasitas e tóxicas. 4 ed. São Paulo: Instituto Plantarum, 2008.

LORENZI, H.; MATOS, F. J. A.. Plantas medicinais no Brasil: Nativas e exóticas. 2 ed. São Paulo: Instituto Plantarum, 2008.

LUCENA, R. F. P.; ALBUQUERQUE, U. P.; FLORENTINO, A. T. N.; FERRAZ, J. S. F.. Useful plants of the semi-arid northeastern region of Brazil: a look at their conservation and sustainable use. Environmental Monitoring and Assessment, v.125, n.1, p.281-290, 2007. DOI: https://doi.org/10.1007/s10661-006-9521-1

LUCENA, R. F. P.; NASCIMENTO, V. T.; ARAÚJO, E. L.; ALBUQUERQUE, U. P.. Local uses of native plants in an area of Caatinga vegetation (Pernambuco, NE Brazil).
Ethnobotany Research and Applications, v.6, p.3-14, 2008. DOI: http://doi.org/10.17348/era.6.0.3-14

MACIEL, M.; GUARIM NETO, G.. Um olhar sobre as benzedeiras de Juruena (Mato Grosso, Brasil) e as plantas usadas para benzer e curar. Boletim do Museu Paranaense Emílio Goeldi, p.61-77, 2006.

MAIOLI-AZEVEDO, V.; FONSECA-KRUEL, V. S.. Plantas medicinais e ritualísticas vendidas em feiras livres no Município do Rio de Janeiro, RJ, Brasil: estudo de caso nas zonas Norte e Sul. Acta Botanica Basilica, v.21, n.2, p.263275, 2007. DOI: http://doi.org/10.1590/S010233062007000200002

MUNIZ, J. C.; SILVA, L. E.. Mais que isso eu não posso falá: notas sobre benzeduras e parteiragens caiçara em Guaraqueçaba/PR. HYGEIA - Revista Brasileira de Geografia Médica e da Saúde, v.12, n.23, p.31-43, 2016.

OLIVEIRA, E. C. S.; TROVÃO, D. M. B. M.. O uso de plantas em rituais de rezas e benzeduras: um olhar sobre esta prática no estado da Paraíba. Revista Brasileira de Biociências, v.7, n.3, 2009.

ROQUE, A. A.; ROCHA, R. M.; LOIOLA, M. I. B.. Uso e diversidade de plantas medicinais da Caatinga na comunidade rural de Laginhas, município de Caicó, Rio Grande do Norte (nordeste do Brasil). Revista Brasileira de Plantas Medicinais, v.12, n.1, p.31-42, 2010. DOI: http://doi.org/10.1590/S1516-05722010000100006

SANTOS, F. V.. O ofício das rezadeiras como patrimônio cultural: religiosidade e saberes de cura em Cruzeta na região do Seridó Potiguar. Revista CPC, n.8, p.6-35, 2009. DOI: https://doi.org/10.11606/issn.1980-4466.v0i8p6-35

SANTOS, R. S.; MOTA, L. H. S.; MARQUES, B. C.; REIS, L. B.; REIS, L. B.; SILVA, C. S.; LIMA, D. A. C; ALBUQUERQUE, W. A.; DEIRÓ, L. X.; AMOR, A. L. M.. Uso regular de plantas medicinais para fins terapêuticos em famílias residentes na zona rural de Santo Antônio de Jesus, Bahia, Brasil. Journal of Health \& Biological Sciences, v.5, n.4, p.364-370, 2017. DOI: http://doi.org/10.12662/23173076jhbs.v5i4.1317.p364-370.2017

SHARMA, U. K.; PEGU, S.. Ethnobotany of religious and supernatural beliefs of the Mising tribes of Assam with special reference to the 'DoburUie'. Journal of Ethnobiology and Ethnomedicine, v.7, n.1, p.16, 2011. DOI: https://doi.org/10.1186/1746-4269-7-16

SILVA, N.; LUCENA, R. F. P.; LIMA, J. R. F.; LIMA, G. D. S.; CARVALHO, T. K. N.; SOUSA JUNIOR, S. P.; ALVES, C. A. B.. Conhecimento e Uso da Vegetação Nativa da Caatinga em uma Comunidade Rural da Paraíba, Nordeste do Brasil. Boletim do Museu de Biologia Mello Leitão, n.34, 2014.

SILVA, P. H.; OLIVEIRA, Y. R.; ABREU, M. C.. Entre símbolos, mistérios e a cura: plantas místicas dos quintais de uma comunidade rural piauiense. Gaia Scientia, v.12, n.1, 2018. DOI: https://doi.org/10.22478/ufpb.19811268.2018v12n1.33196

SIVIERO, A.; DELUNARDO, T. A.; HAVERROTH, M.; OLIVEIRA, L. C.; ROAMN, A. L. C.; MENDONÇA, A. M. S.. Plantas 
ornamentais em quintais urbanos de Rio Branco, Brasil.

Boletim do Museu Paraense Emílio Goeldi, v.9, n.3, 2014.

SOLDATI, G. T.; HANAZAKI, N.; CRIVOS, M.; ALBUQUERQUE, U. P.. Does environmental instability favor the production and horizontal transmission of knowledge regarding medicinal plants? A study in Southeast Brazil. PloS One, v.10, n.5, 2015. DOI:

https://doi.org/10.1371/journal.pone.0126389

TAKWA, S.; CALEJA, C.; BARREIRA, J. C. M.; SOCOVOC, M.; ACHOUR, L.; BARROS, L.; FERREIRA, I. C. F. R.. Arbutus unedo L. and Ocimum basilicum L. as sources of natural preservatives for food industry: A case study using loaf bread. LWT: Food Science and Technology, v.88, p.47-55, 2018. DOI: https://doi.org/10.1016/j.Iwt.2017.09.041

THEOTONIO, A. C. R.. Entre ramos de poder: rezadeiras e práticas mágicas na zona rural de Areia-PB. Monografia
(Graduação em História) - Universidade Federal de Campina Grande, Campina Grande, 2010.

VERDE, A.; RIVERA, D.; OBÓN, C.. Plantas mágicas de la provincia de Albacete: maléficas, protectoras y mágicocurativas. Al-Basit, v.40, p.143-156, 1997.

ZANK, S.; HANAZAKI, N.. Healing faith: knowledge, learning and social relationships of healers from Araripe plateau, Brazil. Ethnobiology and Conservation, v.5, 2016. DOI: http://doi.org/10.15451/ec2016-6-5.3-1-15

ZENT, S.. The Processual perspectives on traditional environmental knowledge: continuity, erosion, transformation, innovation. In: ELLEN, R.; STEPHEN, J. L.; JOHNS, S. E.. Understanding Cultural Transmission in Anthropology: A Critical Synthesis. New York: Berghahn Books, 2013. p.213-265.

A CBPC - Companhia Brasileira de Produção Científica (CNPJ: 11.221.422/0001-03) detém os direitos materiais desta publicação. Os direitos referem-se à publicação do trabalho em qualquer parte do mundo, incluindo os direitos às renovaç̃ões, expansões e disseminações da contribuição, bem como outros direitos subsidiários. Todos os trabalhos publicados eletronicamente poderão posteriormente ser publicados em coletâneas impressas sob coordenação da Sustenere Publishing, da Companhia Brasileira de Produção Científica e seus parceiros autorizados. Os (as) autores (as) preservam os direitos autorais, mas não têm permissão para a publicação da contribuição em outro meio, impresso ou digital, em português ou em tradução. 